Juvenile xanthogranuloma (JXG) is a rare non-Langerhans cell tumour usually diagnosed during infancy. The lesion is typically located in the skin; however, extracutaneous lesions have been described. The symptoms vary depending on the location and size of the lesion.

Presented here is a case of 13-yearold girl with this type of tumour located within the bronchus. She reported chest discomfort, difficulty breathing, and cough. A month prior to admission she had suffered from a respiratory tract infection. Prolonged surgical treatment was required due to the tumour's atypical location and recurrence of the tumour following initial resection.

Isolated pulmonary JXG is an extremely rare finding, which requires accurate diagnosis and careful planning of therapeutic treatment. Severe pulmonary symptoms, inconclusive histopathological examination, malignancy risk, and large tumour size are indications for radical surgical resection of the tumour. Non-surgical treatment with chemotherapy is useful in cases of inoperable tumours.

Key words: chemotherapy, children, juvenile xanthogranuloma, non-Langerhans cell tumour, surgery.

Contemp Oncol (Pozn) 2020; 24 (3): 200-202 DOI: https://doi.org/10.5114/wo.2020.97636

\section{Isolated endobronchial juvenile xanthogranuloma: a case report}

\author{
Patrycja Sosnowska ${ }^{1}$, Patrycja Antosik ${ }^{2}$, Anna Ostałowska², Piotr Nogal ${ }^{3}$, \\ Przemysław Mańkowski ${ }^{1}$
}

${ }^{1}$ Department of Paediatric Surgery, Traumatology and Urology, Poznan University of Medical Sciences, Poznań, Poland

${ }^{2}$ Student Scientific Group of Paediatric Surgery, Poznan University of Medical Sciences, Poznan, Poland

${ }^{3}$ Departament of Otolaryngology, Head and Neck Surgery, Poznan University of Medical Sciences, Poznan, Poland

\section{Introduction}

Juvenile xanthogranuloma (JXG) is a rare non-Langerhans cell disorder [1], which is predominantly diagnosed during the first year of life or is present at birth [2, 3]. It is slightly more frequent in males [3]. Typically JXG involves the skin; however, systemic lesions may rarely appear (3.9-5\%) [4]. Herein we present a case of a 13-year-old girl with isolated bronchial JXG.

\section{Case report}

Herein we present a case of a 13-year-old girl who was admitted to the Department of Paediatric Surgery, Traumatology, and Urology in Poznan. She reported chest discomfort, difficulty breathing, and a cough. A month prior to admission she had suffered from a respiratory tract infection. She was delivered at term as a firstborn child with an Apgar score of 10 and a normal birthweight of $3360 \mathrm{~g}$. At the age of three years, she was diagnosed with erythrocyturia. Clinical examination on admission revealed pallor, left side rib prominence, and diminished vesicular breath sounds on the left (from base to shoulder blade angle). X-ray showed atelectasis of a large part of the superior left lobe and obstruction of the bronchus leading to the third segment of the left lung (Fig. 1).

Computed tomography indicated a soft tissue lesion within the bronchus (Fig. 2).

Bronchoscopy was performed, which revealed a pathological mass filling the left main bronchus (Fig. 3).

Despite the initial recanalisation of only the inferior lobar bronchus, the condition of the patient improved, and a week later the procedure was repeated to clear the superior lobar bronchus. Histopathological examination of the mass indicated an inflammatory myofibroblastic tumour. In the following two months, the tumour recurred and caused symptoms of breathing difficulty. Seven subsequent bronchoscopic decongestions were performed. Due to recurrence, a tissue biopsy was repeated and a second pathomorphological centre was involved in the histopathological interpretation of the biopsy sample. Cytomorphology showed typical Touton cells, and immunohistochemistry was negative for CD1a, s-100, and langerin and positive for CD163. With these results, the patient was diagnosed with juvenile xanthogranuloma. She was referred to an oncological centre for consideration of systemic chemotherapeutic treatment with vinblastine or cytarabine. The patient did not undergo chemotherapy due to the risk of adverse effects, and because the pathological mass was of a stable diameter. The tumour will be monitored, and chemotherapy considered at each future evaluation. 


\section{Discussion}

Juvenile xanthogranuloma is a form of non-Langerhans cell histiocytosis that predominantly affects the skin (Table 1) [5]. The most common JXG manifestation is solitary or multifocal papular nodules varying from yellow through red to brown in colour. They mostly occur on the head and neck, but the trunk and extremities may be affected as well. JXG rarely manifests in extracutaneous locations (5\%). The most frequent site is the eye (0.3-0.5\%) $[2,3,6]$. Extracutaneous JXG lesions have been described in the lung, intestines, liver, spleen, adrenal gland, gonads, central nervous system, bone marrow, and kidney $[2,6]$. The coexistence of cutaneous and extracutaneous lesions occurs in fewer than $50 \%$ of patients [2].

Pulmonary JXG lesions are extremely rare. They are usually multifocal, localised in the pulmonary parenchyma, and accompanied by other cutaneous and extracutaneous lesions. Pulmonary JXG tumours can present as pneumonia, haemoptysis, or airway obstruction, but they can also be asymptomatic [2, 6, 7]. Dehner recorded a three-year-old boy with pneumonia caused by a JXG lesion in the bronchus without skin manifestations, similar to our patient [6]. Biopsy and histopathological examination with immunohistochemistry of JXG are not generally required due to characteristic clinical presentation. However, they are useful in confirmation of diagnosis and differentiation of cell type and immunohistochemistry. Histopathological features of JXG include the presence of Touton cells and infiltrates of dermal histiocytes. Touton giant cells are multinucleated and characterised by peripherally located eosinophilic cytoplasm. They may be present in up to $85 \%$ of cases with skin manifestation but are a less common finding in extracutaneous sites $[3,6,8]$. In immunohistochemistry, JXG is marked by the positivity of marker factor XIIIa, CD163, CD68, CD14, or vimentin and the negativity of CD1a or S-100 protein [3, $6,8]$. According to Kraus et al., neither the presence of S-100 nor the absence of XIIla precludes the diagnosis [9]. Recent studies have reported BRAF and MAP2K1 gene mutations in the course of JXG [10]. In our case, molecular diagnostics have not been performed yet.

Cutaneous lesions are generally benign, self-limiting, and regress spontaneously, and therefore usually do not require treatment. Management of pulmonary JXG depends on several factors. A surgical approach is indicated for lesions with severe symptoms, precarious location, and uncertain histopathological diagnosis at the time of operation. Large extracutaneous lesions can spontaneously regress, but extracutaneous JXG without skin presentation are usually surgically resected [2, 7]. Systemic treatment with vinblastine, prednisone, and methotrexate is reserved for patients with symptomatic JXG or involvement of the central nervous system [8]. Cauro et al. reported a case of a 13-month-old child with cerebellar and pulmonary JXG. Regression of pulmonary lesions after administration of chemotherapy with vinblastine was observed [11]. Maeda et al. described the use of both vinblastine and cytarabine in the treatment of pulmonary JXG lesions [10].

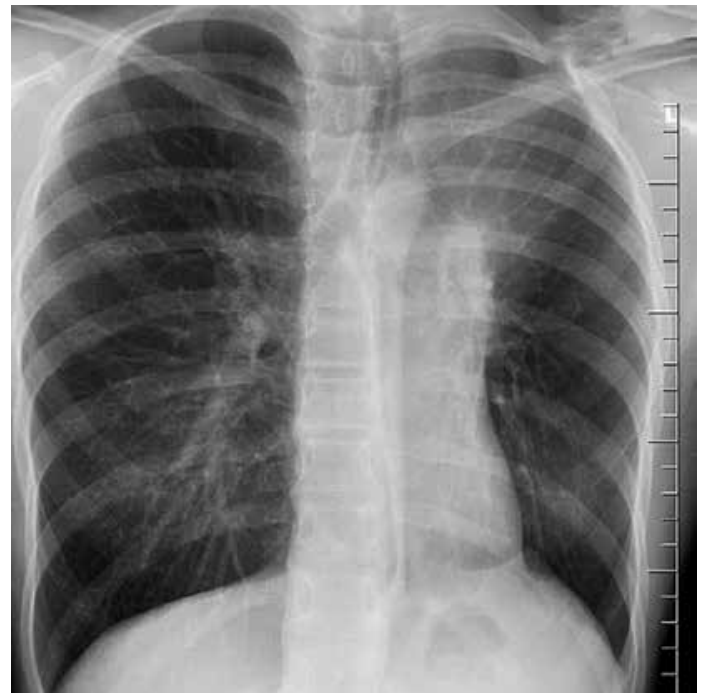

Fig. 1. X-ray showed atelectasis of almost the whole left lung superior lobe and obstruction of the bronchus leading to the third segment of the left lung

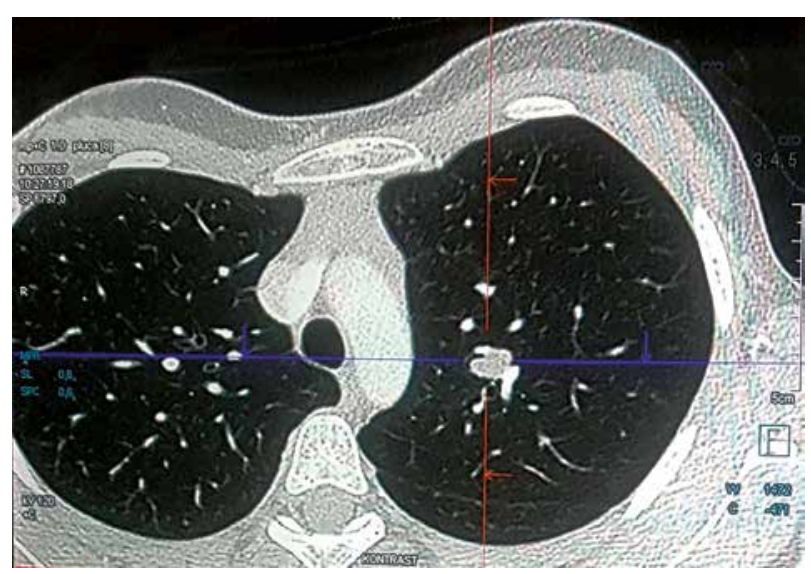

Fig. 2. Computed tomography indicated a soft tissue lesion in the bronchus

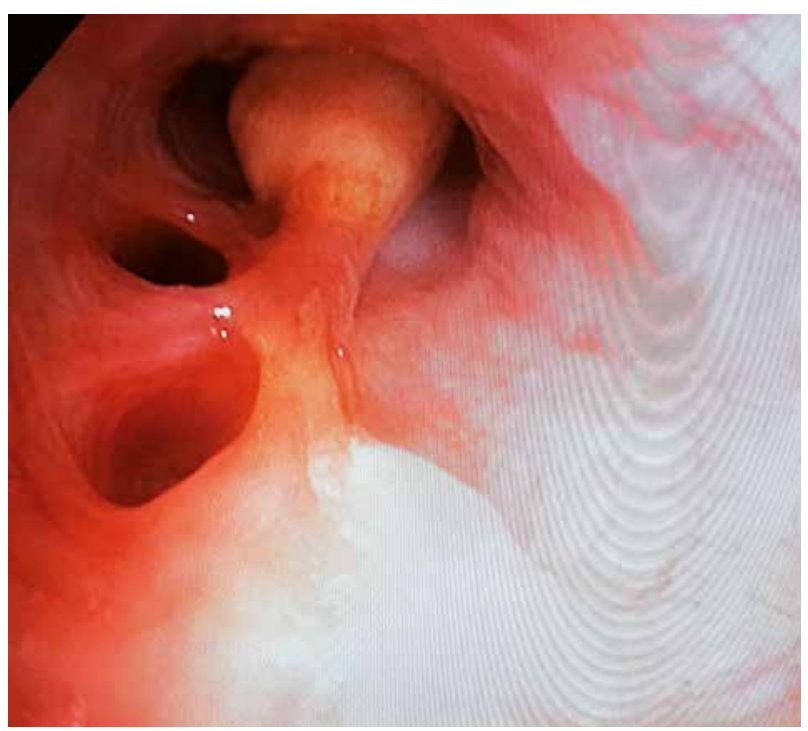

Fig. 3. Bronchoscopy revealed pathological mass filling the left main bronchus 
Table 1. Classification of the cell histiocytosis (group C and L, according to [5])

\begin{tabular}{|c|c|c|c|}
\hline \multicolumn{4}{|c|}{ Non-Langerhans cell histiocytosis classification (group C) } \\
\hline \multicolumn{2}{|c|}{ Cutaneous disease } & \multicolumn{2}{|c|}{ Cutaneous disease with a major systemic component } \\
\hline Xanthogranuloma family & Non-xanthogranuloma family & Xanthogranuloma family & Non-xanthogranuloma family \\
\hline $\begin{array}{c}\text { Juvenile xanthogranuloma } \\
\text { Adult xanthogranuloma } \\
\text { Solitary reticulohistiocytoma } \\
\text { Benign cephalic histiocytosis } \\
\text { Generalized eruptive } \\
\text { histiocytosis } \\
\text { Progressive nodular } \\
\text { histiocytosis }\end{array}$ & $\begin{array}{c}\text { Cutaneous Rosai-Dorfman } \\
\text { disease } \\
\text { Necrobiotic } \\
\text { xanthogranuloma } \\
\text { Cutaneous histiocytoses not } \\
\text { otherwise specified }\end{array}$ & Xanthoma disseminatum & $\begin{array}{l}\text { Multicentric } \\
\text { reticulohistiocytosis }\end{array}$ \\
\hline \multicolumn{4}{|l|}{ Histiocytoses (group L) } \\
\hline Langerhans cell histiocytosis & $\begin{array}{l}\text { Indeterminate cell } \\
\text { histiocytosis }\end{array}$ & Erdheim-Chester disease & $\begin{array}{c}\text { Mixed Erdheim-Chester } \\
\text { disease and Langerhans cell } \\
\text { histiocytosis }\end{array}$ \\
\hline $\begin{array}{l}\text { Langerhans cell histiocytosis } \\
\text { single system } \\
\text { Langerhans cell histiocytosis } \\
\text { lung } 1\end{array}$ & & $\begin{array}{l}\text { Erdheim-Chester disease classical } \\
\text { type } \\
\text { Erdheim-Chester disease without } \\
\text { bone involvement } \\
\text { Associated with another } \\
\text { myeloproliferative/ } \\
\text { myelodysplastic disorder } \\
\text { Extracutaneous or disseminated } \\
\text { juvenile xanthogranuloma with } \\
\text { MAPK activating } \\
\text { mutation or ALK translocations }\end{array}$ & \\
\hline
\end{tabular}

\section{Conclusions}

The clinical manifestation of JXG depends on the location of the tumour, which may be multifocal, involving both the skin and extracutaneous tissues. Isolated pulmonary JXG is an extremely rare finding, which requires correct diagnosis and careful planning of therapeutic treatment. Due to the low number of cases and lack of guidelines, it can be difficult to choose the best treatment option. Management of JXG should be based on the child's age, lesion location, and clinical manifestations. Severe pulmonary symptoms, inconclusive histopathological examination, risk of malignancy, and large tumour size are indications for radical surgical resection of the tumour. Non-surgical treatment with chemotherapy is useful in cases of inoperable tumours. However, it is crucial to consider the advantages and disadvantages of both methods. More comparative studies are required to investigate management strategies.

The authors declare no conflict of interest.

\section{References}

1. Zelger B, Burgdorf WH. The cutaneous „histiocytoses”. Adv Dermatol 2001; 17: 77-114.

2. Murphy JT, Soeken T, Megison S, Perez E. Juvenile xanthogranuloma: diverse presentations of noncutaneous disease. J Pediatr Hematol Oncol 2014; 36: 641-645.

3. Pajaziti L, Hapciu SR, Pajaziti A. Juvenile xanthogranuloma: a case report and review of the literature. BMC Res Notes 2014; 7: 174
4. Bakir B, Unuvar E, Terzibasioglu E, Guven K. Atypical lung involvement in a patient with systemic juvenile xanthogranuloma. Pediatr Radiol 2007; 37: 325-327.

5. Emile JF, Abla O, Fraitag S, et al. Revised classification of histiocytoses and neoplasms of the macrophage-dendritic cell lineages. Blood 2016; 127: 2672-2681.

6. Dehner LP. Juvenile xanthogranulomas in the first two decades of life: a clinicopathologic study of 174 cases with cutaneous and extracutaneous manifestations. Am J Surg Pathol 2003; 27: 579-593.

7. Naiman AN, Bouvier R, Colreavy MP, Bellon G, Froehlich P. Tracheal juvenile xanthogranuloma in a child. Int J Pediatr Otorhinolaryngol 2004; 68: 1469-1472

8. Dalia S, Shao H, Sagatys E, Cualing H, Sokol L. Dendritic cell and histiocytic neoplasms: biology, diagnosis, and treatment. Cancer Control 2014; 21: 290-300.

9. Kraus MD, Haley JC, Ruiz R, Essary L, Moran CA, Fletcher CD. „Juvenile" xanthogranuloma: an immunophenotypic study with a reappraisal of histogenesis. Am J Dermatopathol 2001; 23: 104-111.

10. Maeda M, Morimoto A, Shioda Y, et al. Long-term outcomes of children with extracutaneous juvenile xanthogranulomas in Japan. Pediatr Blood Cancer 2020; 67: e28381.

11. Cauro F, Houtteville JP, Mesnil JL, Guarnieri J. Cerebellar, pulmonary and cutaneous localizations of juvenile xanthogranuloma. Ann Dermatol Venereol 2002; 129: 307-310.

\section{Address for correspondence}

\section{Patrycja Sosnowska}

Department of Pediatric Surgery, Traumatology and Urology Poznan University of Medical Sciences

27/33 Szpitalna St.

60-572 Poznań, Poland

e-mail: patrycja.sosnowska@outlook.com

Submitted: 5.04.2020

Accepted: 23.06 .2020 